\title{
Prevalence and associated factors of hypertension in Amhara regional state city and its' surrounding rural districts: a community-based cross-sectional study
}

\author{
Tadesse Dagget Tesfaye, Worku Animaw Temesgen, Ayele Semachew Kasa, \\ Yeshaneh Seyoum Yismaw
}

Department of Adult Health Nursing, College of Medicine and Health Sciences, Bahir Dar University, Bahir Dar, Ethiopia.

Emails: tadesse.dagget@yahoo.com/tadessed@bdu.edu.et, workimaw@gmail.com, finoteayu24@gmail.com, yeshanehs@gmail.com

\begin{abstract}
Background: Nowadays, among non-communicable diseases hypertension is a growing public health important disease both in developed and developing nations.

Objective: The aim of this study was to determine the prevalence and associated factors of hypertension in Amhara Regional State city and its' surrounding rural districts, Ethiopia.

Method: Community-based cross-sectional study was conducted in the urban and rural communities living in Amhara Regional State city and its' surrounding rural districts administrations in 2015. The WHO Stepwise approach was used for data collection. Result: A total of 1405 subjects participated and the response rate was $95.5 \%$. The overall prevalence of hypertension was $11.4 \%$ either previously diagnosed or undiagnosed and was higher in older ages. Whereas the prevalence of hypertension was $13 \%$ for urban and 10\% for rural residents. Nearly half of them $(46.3 \%)$ were newly diagnosed. A family history of hypertension, being underweight, overweight, obese, and raised fasting blood sugar were found to be significantly associated with raised blood pressure.
\end{abstract}

Conclusion: One among every three $(37.4 \%)$ and one among every nine study participants were found to have pre-hypertension and hypertension respectively.

Keywords: Prevalence of hypertension, blood pressure, Bahir Dar.

DOI: https://dx.doi.org/10.4314/ahs.v19i3.34

Cite as: Tesfaye TD, Temesgen WA, Kasa AS, Yismaw YS. Prevalence and associated factors of bypertension in Ambara regional state city and its' surrounding rural districts: a community-based cross-sectional study. Afri Health Sci. 2019;19(3): 2580-2590. bttps:/ / dx.doi.org/10.4314/abs.v19i3.34

\section{Introduction}

The growing burden of non-communicable diseases (NCDs) represents a major challenge to health development. NCDs are responsible for a high proportion of death and disability burden around the globe. In developing countries, the burden of disease caused by NCDs is increasing rapidly and will have significant social, economic, and health consequences ${ }^{1}$. In sub-Saharan Afri-

\section{Corresponding author: \\ Tadesse Dagget Tesfaye, \\ Department of Adult Health \\ Nursing, College of Medicine \\ and Health Sciences, Bahir Dar University, \\ Bahir Dar, Ethiopia. \\ Email: tadesse.dagget@yahoo.com}

ca, NCDs are projected to surpass infectious diseases by $2030^{2}$.

Hypertension is a NCD which, also known as high or raised blood pressure, is a global public health issue. It rarely causes symptoms in the early stages and many people go undiagnosed. It contributes to the burden of heart disease, stroke, kidney failure, premature mortality, and disability. It disproportionately affects populations in low- and middle-income countries where health systems are weak. Globally, the overall prevalence of Hypertension in adults aged 18 years and above in 2014 was $22 \%{ }^{3}$, around $40 \%$ in people $\geq 25 y e a r s, 46 \%$ in Africa region and $35 \%$ in Americas in 2008. Moreover, it was estimated to cause 7.5 million deaths, about $12.8 \%$ of the total of all deaths worldwide ${ }^{4}$.

In Africa, hypertension cases are increasing from time to time, in 1990 the prevalence was $19.7 \%$ and it grew to an

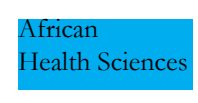

2580
(C) 2019 Tesfaye et al. Licensee African Health Sciences. This is an Open Access article distributed under the terms of the Creative commons Attribution License (https://creativecommons.org/licenses/BY/4.0), which permits unrestricted use, distribution, and reproduction in any medium, provided the original work is properly cited. 
overall pooled prevalence of $30.4 \%$ in 2010 . It was estimated that 130.2 million people had hypertension. However, it is projected that there will be 216.8 million cases of hypertension by 2030 . Besides, many hypertensive individuals are not aware of their condition ${ }^{5}$.

A systematic review and meta-analysis conducted in 2014 to assess the recent burden of hypertension in sub-Saharan Africa in the last 14 years showed that hypertension prevalence varied widely across the studies ranging from $15 \%-70 \%{ }^{6}$.

In Ethiopia, a cross-sectional study conducted on adults aged $\geq 35$ years in the rural and urban communities of Dabat district and Gondar town in 2012 showed that overall prevalence of hypertension was $27.9 \%$ with the proportion of the urban and rural residents being $30.7 \%$ and $25.3 \%$ respectively ${ }^{7}$.

A systematic review and meta-analysis on subjects aged 15 years and above showed that the prevalence of hypertension among Ethiopian population was estimated to be $19.6 \%$, and that the prevalence was higher in the urban population $(23.7 \%)$ than in rural and urban combined $14.7 \%$. The prevalence of hypertension among males was $20.6 \%$ and females $19.2 \%$ was similar. This study found that the prevalence of hypertension in Ethiopia is increasing.

The overall prevalence of hypertension among adults in Durame Town, Southern Ethiopia in 2013 was found to be $22.4 \%$. Besides this study also showed that older age, male sex, having a family history of hypertension, physical inactivity, poor vegetable diet, additional salt consumption and obesity were important risk factors associated with hypertension?.

Studies have shown risk factors such as age, sex, obesity, physical activity, and family history have a significant association with hypertension ${ }^{9-11}$.

Most studies done on hypertension incorporate 25 years and above which would over-estimate the overall prevalence of hypertension in the community hence this study resolved this gap by considering people aged 18 years and above at the bottom and 65 years and above at the top. The main objective of the study was to quantify the prevalence of hypertension and its associated factors among in Amhara Regional State city and its' surrounding rural districts' community in Ethiopia.

Early detection, intervention, and avoidance of risk fac- tors for hypertension have a significant contribution to the reduction of the burden of hypertension. Therefore, quantifying the magnitude and risks of hypertension is crucial. This community-based study which included the urban and rural community, young to old participants with large age range would share its own contribution especially showing the magnitude and associated factors of hypertension in the capital city of Amhara Regional State and its' surrounding rural districts, NorthWest Ethiopia. Besides, it would help stakeholders to design and intervene based on scientific evidence.

\section{Methods and material}

Study design and period: A Community-based cross-sectional study was conducted in 2015.

Study area: The study was conducted in Bahir Dar, capital city of Amhara Regional State and its' surrounding rural districts. Bahir Dar is a capital city of Amhara regional state located $565 \mathrm{Km}$ from Addis Ababa to North West Ethiopia. Based on central statistical agency Ethiopian Demographic and Health Survey EDHS report of 2011 the city has estimated total population of $274,836.5^{12}$.

Study population: The study populations were all individuals aged 18 and above in Bahir Dar city and Bahir Dar Surrounding rural districts. The study units were sampled individuals from Bahir Dar city and surrounding Kebeles.

Inclusion and exclusion criteria: All sampled individuals aged $\geq 18$ years old were included in the study. Pregnant women, mothers in the post-partum period, and individuals who were severely ill were excluded from the study.

Sample size and sampling procedure: This study was a part of a large study that studied diabetes mellitus (DM). Hence the sample size was determined by the prevalence of DM so as to gain a large sample size. The sample size was calculated by using EPI INFO stat calc for the two population proportions by taking the prevalence of urban DM to be $5.1 \%$ and that of rural DM to be $2.1 \%$ from the study done in Gondar ${ }^{13}$ and taking 95\% confidence interval, $80 \%$ power and $10 \%$ of non-response rate. Accordingly, the total calculated sample size became 1472 for urban and 736 for rural settings.

A multistage cluster and random sampling strategy was employed to select study participants from urban and ru- 
ral districts. Initially, clusters of 12 Kebeles/'Kebele' is the smallest administrative units in Ethiopia/ for both urban and rural were selected using simple random sampling from the list of the district.

Then, households were selected from each kebele proportional to the number of eligible individuals in each kebele using systematic random sampling technique. Finally, the study unit individual participants from each house hold were selected using a lottery method.

\section{Study variables}

Independent variables: included socio-demographic variables residence, age, sex, marital status, educational status, religion, occupation and ethnicity, lifestyle feeding habit, daily activity, regular exercise, Khat chewing (a natural stimulant with amphetamine-like effects commonly used for social recreation in East African countries), smoking, alcohol consumption; anthropometric measurements, that is; Body mass index [BMI], waist circumference [WC], waist to hip ratio[WHR], blood pressure $[\mathrm{BP}]$, and health profile related variable; that is, family history of hypertension

\section{Dependent variable: Status of hypertension}

Data collection and procedures: The data was collected by 24 nurses and laboratory technicians using structured and pre-tested questionnaire. Data collectors were given two days training on data collection techniques before starting data collection. The questionnaire has been adapted from World Health Organization WHO for NCDs surveillance in developing countries ${ }^{14}$.

Data were collected in accordance with the STEP-wise approach of the WHO for NCDs surveillance in developing countries ${ }^{14}$. The approach has two levels: 1) questionnaire to gather demographic and behavioral information, 2) simple physical measurements weight, height, waist circumference and hip circumference and 3) fasting blood sugar measurement. In accordance with the STEPS manual, questions related to alcohol and substance use were tailored to reflect the local context of Ethiopia ${ }^{14}$. A few additional questions were added to supplement the questionnaire and to reflect the local context of Ethiopia. Data regarding socio -demographic variables, health profile variables, and lifestyle were collected by interview. Anthropometric measurements were taken without heavy outdoor clothing. Stature was measured to the nearest millimeter using an Anthropometric rod. Weight was measured on a pre-standardized digital body weighing scale, and BMI calculated using the formula weight in kilogram divided by height in meters squared. The hip circumference was measured at the maximum circumference around the hips and the waist circumference obtained at the level of the umbilicus at the midpoint between the lower margin of the last palpable posterior rib and the top of the iliac crest hip bone using an inelastic measuring tape while the participants were standing erect. In this study the researchers used a manual BP measuring device Ce/ISO Approved Medical Adult Aneroid Sphygmomanometer MT01028001 to measure study participants blood pressure with participants sitting after resting for at least five minutes. Three measurements of BP on a single visit were taken at least one minute apart, and the averages of the records used for computation of the results. At least two visits were made for those study participants whose BP were elevated at the first contact.

\section{Operational definitions}

Underweight: $\mathrm{BMI}<18.5 \mathrm{~kg} / \mathrm{m}^{2}$

Normal Weight: BMI 18.5-24.9 kg/m²

Overweight: BMI $25.0-29.9 \mathrm{~kg} / \mathrm{m}^{2}$

Obese: $\mathrm{BMI}>30.0 \mathrm{~kg} / \mathrm{m}^{2}$

Centrally obese: waist-hip ratio (WHR) $>0.95$ for men and 0.85 for women ${ }^{15}$.

Normotensive*: systolic $\mathrm{BP}<120 \mathrm{mmHg}$ and diastolic $\mathrm{BP}<80 \mathrm{mmHg}$

Pre-hypertension*: average of two consecutive systolic BP $120-139 \mathrm{mmHg}$ or diastolic BP $80-89 \mathrm{mmHg}$;

Hypertension*: systolic BP $\geq 140 \mathrm{mmHg}$ and or diastolic $\mathrm{BP} \geq 90 \mathrm{mmHg}$

$*=$ if test result falls in different categories either for systolic or diastolic BP measurement the highest measurement value used to categorize individuals BP status.

Data quality control measures: The standardized questionnaire has adapted from WHO STEPs NCDs surveillance in developing countries ${ }^{14}$. Some questions were added to address the local context and tested for the accuracy and consistency of the tool before actual data collection.

The English version questionnaire was translated to the local language (Amharic) and transcribed back into the English language. The questionnaire was pre-tested in 5\% 
of the total calculated sample sizes in similar settings, and these were not included in actual study, modified as necessary for clarity, sensitiveness, completeness, and reliability of some newly incorporated questions.

Furthermore, the supervisors and the principal investigators monitored the overall data collection process. For easier understanding of terms in the questionnaire, data collectors and supervisors trained and practiced the questionnaire before the actual data collection. Completion, accuracy, and clarity of the collected data was checked carefully on a regular basis.

Data processing: Data were entered into EPI info 3.5.1 then transferred to IBM SPSS Version 20 Statistics for windows for data cleaning, coding, and analysis. The dependent variable, blood pressure, was dichotomized into hypertensive and not hypertensive. To explain the study population in relation to relevant variables, frequencies, mean values and other summary statistics were used and presented in tables and figures. Both bivariate and multivariable logistic regression models were used to identify associated factors for hypertension. Variables having $\mathrm{P}$-value $\leq 0.20$ in the bivariate analysis were retained in the multivariable model to control the effect of confounders. The Hosmer-Lemeshow goodness of fit statistic was used to assess the fitness of the model. Odds ratios (OR) with their 95\% confidence intervals 95\% CI were calculated to measure the strength of association. $\mathrm{P}$ value $<0.05$ was considered as statistically significant.

\section{Results}

A total of 1,472 participants were involved in this study and 1405 subjects responded which makes it a 95.5\% response rate. Half of the participants $50.8 \%$ were urban dwellers and the remaining rural dwellers. The mean age of participants was found to be $36.99 \pm 15.71$ years old, and ranged from 18 to 97 years old. More than half $56.7 \%$ of the participants were females Table 1.

Table 1. Socio-demographic Characteristics of Study Participants in North West Ethiopia, $2015(\mathrm{~N}=1405)$

\begin{tabular}{|c|c|c|c|}
\hline Variable & Variable Category & Frequency & Percent \\
\hline \multirow[t]{2}{*}{ Residence } & Urban & 691 & 49.2 \\
\hline & Rural & 714 & 50.8 \\
\hline \multirow[t]{2}{*}{ Sex } & Male & 609 & 43.3 \\
\hline & Female & 796 & 56.7 \\
\hline \multirow{6}{*}{ Age Category } & $18-23$ Years & 297 & 21.1 \\
\hline & $24-34$ Years & 445 & 31.7 \\
\hline & $35-44$ Years & 246 & 17.5 \\
\hline & $44-54$ Years & 189 & 13.5 \\
\hline & $55-64$ Years & 134 & 9.5 \\
\hline & $>=65$ Years & 94 & 6.7 \\
\hline \multirow[t]{4}{*}{ Marital Status } & Single & 324 & 23.1 \\
\hline & Married & 924 & 65.8 \\
\hline & Divorced & 72 & 5.1 \\
\hline & Widowed & 84 & 6.0 \\
\hline \multirow[t]{5}{*}{ Educational Status } & Unable to read and Write & 525 & 37.4 \\
\hline & Only read and write & 208 & 14.8 \\
\hline & Grade $1-8$ & 244 & 17.4 \\
\hline & Grade $9-12^{\text {th }}$ & 227 & 16.2 \\
\hline & Diploma and above & 201 & 14.3 \\
\hline \multirow[t]{3}{*}{ Religion } & Orthodox & 1287 & 91.6 \\
\hline & Muslim & 98 & 7.0 \\
\hline & Protestant & 19 & 1.4 \\
\hline \multirow[t]{6}{*}{ Occupation } & Student & 112 & 8.0 \\
\hline & Employed & 161 & 11.5 \\
\hline & Merchant & 142 & 10.1 \\
\hline & Farmer & 424 & 30.2 \\
\hline & House Wife & 349 & 24.8 \\
\hline & Daily laborer and have no regular occupation & 217 & 15.4 \\
\hline
\end{tabular}




\section{Lifestyle}

\section{Feeding / dietary habits of Study Subjects}

Almost half of the participants, $(49.3 \%)$ reported that they ate vegetables and fruits in each week. Regarding frequency of vegetable and fruit consumptions, half of the participants $(50.8 \%)$ reported that they did not eat vegetables and fruits within a week whereas 548(39\%) ate vegetables for 1-3 days per week and $143(10.2 \%)$ ate vegetables for 4 - 7 days/week.

More than two third of the participants $(66 \%)$ reported they eat fat while eating meat. Besides, 867 (61.8\%) participants had a habit of eating raw not cooked meat.

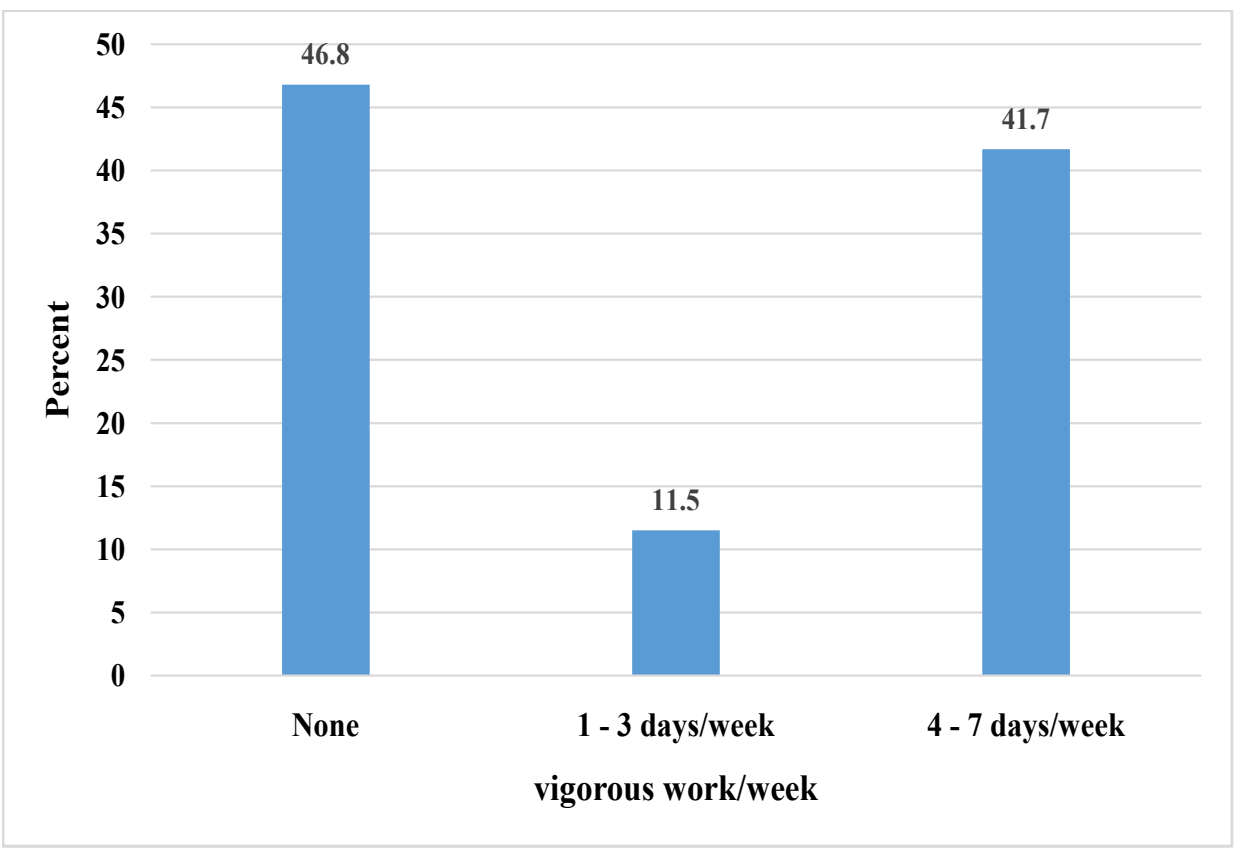

Figure 1. Participants' vigorous work/week, North West Ethiopia 2015.

\section{Physical exercise}

More than half of the participants (53.2\%) reported that their work involved vigorous-intensity activity like lifting and digging. More than two thirds $(68.2 \%)$ of the participants walked or used a bicycle to get to and from places. One hundred seventeen $(8.3 \%)$ study participants reported that they engaged in vigorous sport activities. The majority of participants $(46.8 \%)$ didnot engage in vigorous work/week Figure 1.

\section{Cigarette smoking, alcohol, and Khat chewing}

Thirteen $(0.93 \%)$ participants stated that they smoked cigarette at least once in their life. While only 5 sub- jects $(0.36 \%)$ were smoking at the point of data collection period and reported 8 cigarettes or more every day. Regarding participants' alcohol use 1139 (81.10\%) ever drunk alcohol and 1114 (79.30\%) were drinking alcohol during the data collection period. In the past 12 months, among participants who were drinking alcohol $n=1114$, the frequency of alcohol consumption was reported as occasionally 520(46.7\%), weekly $456(40.9 \%)$ and daily 138(12.4\%). The types of most used alcohol were "Tela" a 1041(93.45\%), "Areki" 210(14.95\%), Beer 181(12.88\%), Wuski 61(4.34\%), and "Teji”" 35 (2.5\%).

Seventy-six (5.41\%) participants ever chewed khat and $654.63 \%$ were chewing khat in the study period.

$\mathrm{a}=$ locally prepared beverage /alcohol in Ethiopia 


\section{Family history of hypertension}

One hundred forty-one (10\%), 4(0.28\%), 16(0.43\%), and $66(4.7 \%)$ participants reported they had a family history of hypertension, stroke, heart attack and diabetes mellitus respectively.

\section{Physical measurements}

The mean values of weight was $55.04 \pm 9.08$ kilograms, height was $1.62 \pm 0.88$ meters, waist circumference was $79.85 \pm 10.51$ centimeters, waist to hip ratio was 0.88 $\mathrm{SD}=0.08$. Participants mean BMI was $21.10 \pm 3.24 \mathrm{Kg} /$ $\mathrm{m}^{2}$. When the BMI score of the participants was categorized according to the definition given above 130 (9.3\%) of the participants were found to be overweight while 30 (2.1\%) were obese. For the waist to hip ratio WTHR 38.9 $\%$ (547) had central obesity. WTHR > 0.95 for men and 0.85 for women in Table 2.

Table 2. Mean value of physical measurements by sex, North West Ethiopia 2015. $(n=1405)$

\begin{tabular}{|c|c|c|c|c|c|c|c|}
\hline \multirow{3}{*}{$\begin{array}{ll} & \text { Variable } \\
\text { Weight }(\mathrm{Kg}) & \end{array}$} & \multicolumn{6}{|c|}{ Mean \pm SD } & \multirow{3}{*}{$\begin{array}{l}\text { p-Value } \\
<0.001\end{array}$} \\
\hline & \multicolumn{2}{|c|}{ Overall } & \multicolumn{2}{|c|}{ Male } & \multicolumn{2}{|c|}{ Female } & \\
\hline & 55.0 & 9.1 & 56.8 & 8.7 & 53.7 & 9.1 & \\
\hline Height (m) & 1.62 & 0.09 & 1.66 & 0.09 & 1.58 & 0.07 & $<0.001$ \\
\hline Waist circumference $(\mathrm{cm})$ & 79.9 & 10.5 & 78.8 & 9.2 & 80.6 & 11.4 & 0.0018 \\
\hline Hip circumference $(\mathrm{cm})$ & 91.2 & 9.9 & 88.9 & 8.4 & 93.0 & 10.6 & $<0.001$ \\
\hline BMI $\left(\mathrm{kg} / \mathrm{m}^{2}\right)$ & 21.1 & 3.4 & 20.5 & 3.1 & 21.5 & 3.5 & $<0.001$ \\
\hline Waist to hip ratio & 0.876 & 0.081 & 0.887 & 0.061 & 0.867 & 0.092 & $<0.001$ \\
\hline Fasting blood glucose level (mg/dl) & 91.2 & 21.3 & 90.7 & 21.5 & 91.5 & 21.2 & 0.48 \\
\hline
\end{tabular}

BMI: Body Mass Index, SD: Standard Deviation

\section{Prevalence of hypertension}

The overall prevalence of hypertension was 11.4\% [95\% CI 11.0, 13.0] including either previously diagnosed or undiagnosed. For the urban resident participants the prevalence of hypertension was $13.0 \%$ [95\% CI: 10.0, 15.0] and while it was lower for rural residents i.e 10.0\% [95\%CI: 8.0, 12.0]. Eleven percent of males [95\% CI: 8.0, 13.0] and twelve percent of females [95\% CI: 10.0, 14.0] were found to be hypertensive in this study.
Systolic and diastolic BP mean were $113.48 \pm 16.78 \mathrm{mmHg}$ and $71.96 \pm 11.56 \mathrm{mmHg}$ respectively.

More than half of the participants were found to have normal blood pressure (51.2\%) and from these, $23.20 \%$ (326) were urban, and 28\% (393) rural dwellers.

Five hundred twenty-six $(37.4 \%)$ were found to be pre-hypertensive among these $19.64 \%$ (276) were urban dwellers, and 17.79\% (250) rural dwellers. And 51.2\% (719) were normotensive among these $23.2 \%$ (326) were urban and (393) 28\% were rural dwellers Figure 2. 


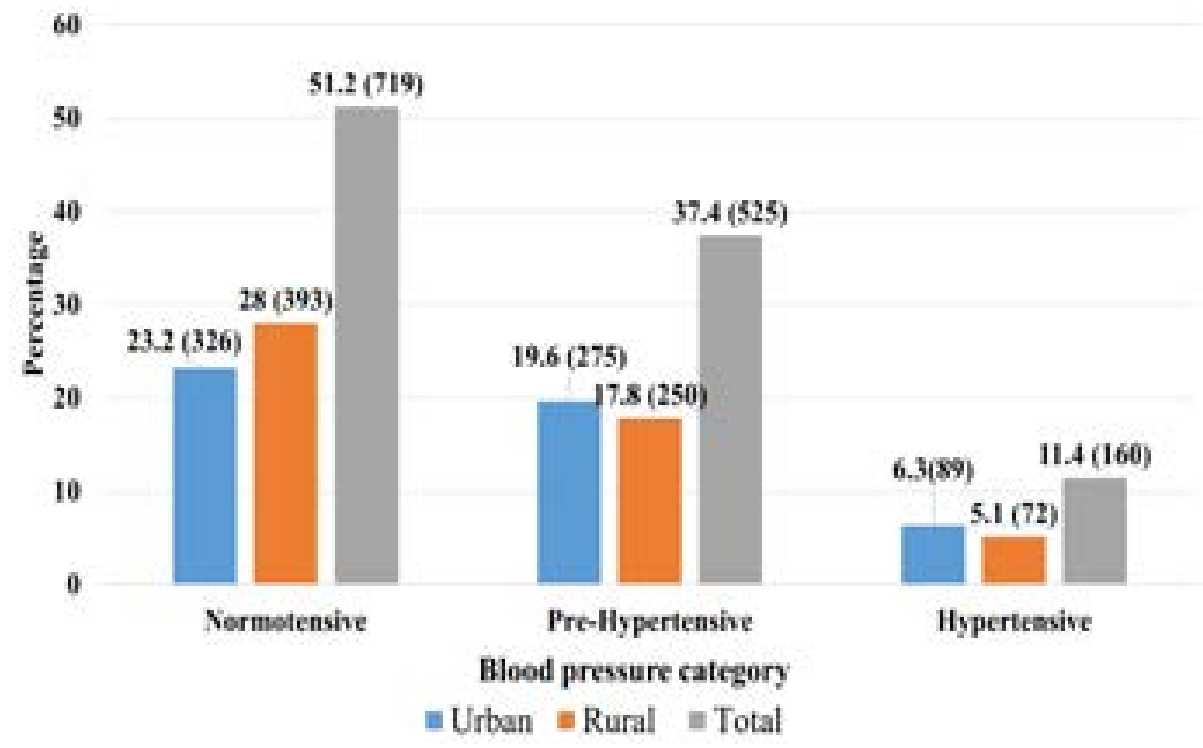

Figure 2. Blood pressure category of study participants by residence in Northwest Ethiopia, 2015.

About $2 / 3 \mathrm{r}^{\mathrm{ds}}(62.28 \%)$ of the study participants reported that they had never had their BP measured.

Among 160 hypertensive cases, over half(53.75\%) of them were known hypertensive individuals and the rest $46.25 \%$ had never had their BP measured and hence they were new hypertensive cases identified by this survey. The mean, median, mode, the minimum and maximum age for subjects with hypertension was 50.71, 50, 60, 20 and 90 years respectively. As the age increased, the prevalence of hypertension was also found to increases Figure 3.

\section{Factors associated with hypertension}

The odds of having hypertension increased in a trend fashion as age increased from younger to older. Study participants who were in the age group $35-44$ years had higher odds of hypertension (aOR: 6.62, 95\% CI: 2.17 to 17.72) compared to those in 18-23 years category. Subjects aged 65 years and above compared to younger 18-23 years had a strong association with the odds of hypertension (aOR: $27.2095 \%$ CI: 8.96 to 82.57). Table 3.

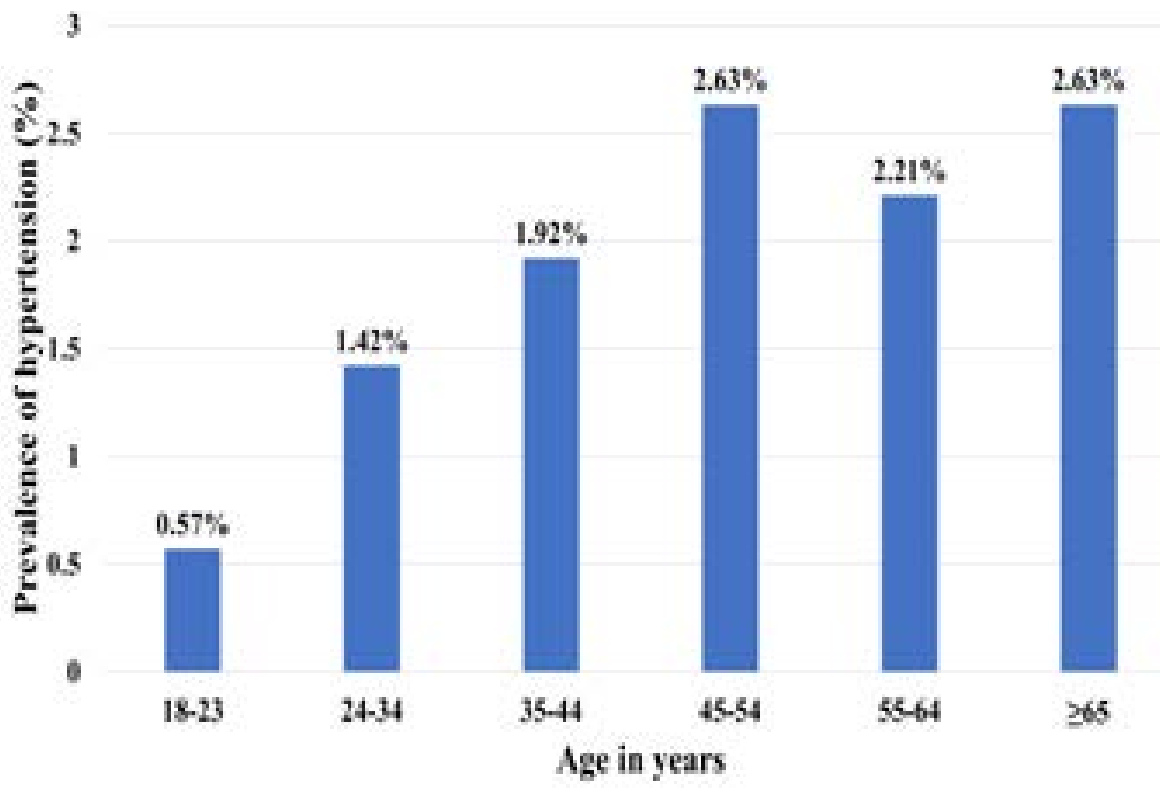

Figure 3:Prevalence of hypertension across age groups among study participants, Northwest Ethiopia, 2015. 
Table 3. Bivariate and multivariate logistic regression analysis of factors associated with hypertension among study participants in North West Ethiopia, $2015(\mathrm{~N}=1405)$

\begin{tabular}{|c|c|c|c|c|c|}
\hline \multirow[b]{2}{*}{ Variable } & & \multicolumn{2}{|c|}{ Hypertension } & \multirow{2}{*}{$\begin{array}{l}\text { Unadjusted OR } \\
(95 \% \mathrm{CI})\end{array}$} & \multirow{2}{*}{$\begin{array}{l}\text { Adjusted OR } \\
(95 \% \mathrm{CI})\end{array}$} \\
\hline & & Yes & No & & \\
\hline \multirow[t]{2}{*}{ Residence } & Urban & $89(6.3 \%)$ & $602(42.8 \%)$ & $1.34(0.96,1.86)$ & $0.82(0.48,1.41)$ \\
\hline & Rural & $71(5.1 \%)$ & $643(45.8 \%)$ & 1.00 & 1.00 \\
\hline \multirow[t]{6}{*}{ Age category } & $18-23$ Years & $8(0.57 \%)$ & $289(20.57 \%)$ & 1.00 & 1.00 \\
\hline & $24-34$ Years & $20(1.42 \%)$ & $425(30.25 \%)$ & $1.70(0.74,3.91)$ & $2.08(0.77,5.60)$ \\
\hline & $35-44$ Years & $27(1.92 \%)$ & $219(15.59 \%)$ & $4.45(1.99,9.99)$ & $6.20(2.17,17.72)^{*}$ \\
\hline & $44-54$ Years & $37(2.63 \%)$ & $152(10.82 \%)$ & $8.79(3.99,19.36)$ & $11.42(3.99,32.69)^{*}$ \\
\hline & $55-64$ Years & $31(2.20 \%)$ & $103(7.33 \%)$ & $10.87(4.84,24.42)$ & $14.13(4.79,41.63)^{*}$ \\
\hline & $>=65$ Years & $37(2.63 \%)$ & $57(4.06)$ & $23.45(10.38,52.99)$ & $27.20(8.96,82.57)^{*}$ \\
\hline \multirow[t]{4}{*}{ Marital Status } & Single & $16(1.1 \%)$ & $308(21.9 \%)$ & 1.00 & 1.00 \\
\hline & Married & $105(7.5 \%)$ & $819(58.3 \%)$ & $2.46(1.43,4.24)^{*}$ & $0.81(0.40,1.67)$ \\
\hline & Divorced & $14(1 \%)$ & $58(4.1 \%)$ & $4.64(2.15,10.03)^{*}$ & $1.89(0.73,4.90)$ \\
\hline & Widowed & $24(1.7 \%)$ & $60(4.3 \%)$ & $7.7(3.86,15.35)^{*}$ & $1.26(0.50,3.19)$ \\
\hline \multirow[t]{6}{*}{ Educational Status } & Unable to read and & $71(5.1 \%)$ & $454(32.3 \%)$ & 1.00 & 1.00 \\
\hline & Write & & & & \\
\hline & Only read and write & $29(2.1 \%)$ & $179(12.7 \%)$ & $1.03(0.65,1.65)$ & $1.10(0.64,1.89)$ \\
\hline & Grade $1-8$ & $30(2.1 \%)$ & $214(15.2 \%)$ & $0.89(0.57,1.42)$ & $1.31(0.73,2.36)$ \\
\hline & Grade $9-12$ & $14(1 \%)$ & $213(15.2 \%)$ & $0.42(0.23,0.76)^{*}$ & $0.73(0.33,1.62)$ \\
\hline & Diploma and above & $16(1.1 \%)$ & $185(13.2 \%)$ & $0.55(0.31,0.98)^{*}$ & $1.10(0.47,2.58)$ \\
\hline \multirow[t]{6}{*}{ Occupation } & Employed & $13(0.9 \%)$ & $148(10.8 \%)$ & 1.00 & 1.00 \\
\hline & Student & $9(0.6 \%)$ & $103(7.3 \%)$ & $0.08(0.41,2.41)$ & $3.09(1.00,9.55)$ \\
\hline & Merchant & $14(1 \%)$ & $128(9.1 \%)$ & $0.99(0.56,2.74)$ & $1.44(0.56,3.68)$ \\
\hline & Farmer & $41(2.9 \%)$ & $383(27.3 \%)$ & $1.24(0.63,2.33)$ & $0.85(0.33,2.23)$ \\
\hline & House Wife & $51(3.6 \%)$ & $298(21.2 \%)$ & $1.21(1.02,3.69)^{*}$ & $0.90(0.39,2.11)$ \\
\hline & $\begin{array}{l}\text { Daily laborer and have } \\
\text { no regular Occupation }\end{array}$ & $32(2.3 \%)$ & $185(13.2 \%)$ & $1.94(0.99,3.88)$ & $1.26(0.53,2.98)$ \\
\hline Do you consume & Yes & $71(5.05 \%)$ & $621(44.2 \%)$ & $1.25(0.90,1.73)$ & $0.71(0.47,1.06)$ \\
\hline vegetable and fruit & No & $89(6.33 \%)$ & $624(44.41 \%)$ & 1.00 & 1.00 \\
\hline weekly & & & & & \\
\hline \multirow[t]{2}{*}{ Family History of HTN } & Yes & $40(2.8 \%)$ & $101(7.2 \%)$ & $3.78(2.50,5.70)^{*}$ & $3.07(1.88,5.02)^{*}$ \\
\hline & No & $120(8.54 \%)$ & $1116(81.42 \%)$ & 1.00 & 1.00 \\
\hline \multirow[t]{4}{*}{ Body mass index/BMI/ } & Datasets Weight & $93(6.6 \%)$ & $857(61 \%)$ & 1.00 & 1.00 \\
\hline & Under Weight & $20(1.4 \%)$ & $275(19.6 \%)$ & $0.67(0.40,1.10)$ & $0.54(0.31,0.93)^{*}$ \\
\hline & Over Weight & $37(2.6 \%)$ & $93(6.6 \%)$ & $3.66(2.36,5.67)^{*}$ & $2.66(1.55,4.56)^{*}$ \\
\hline & Obese & $10(0.7 \%)$ & $20(1.4 \%)$ & $4.6(2.09,10.13)^{*}$ & $3.46(1.34,8.92)^{*}$ \\
\hline Waist to hip ratio & & & & $54.58(7.08,383.9)^{*}$ & $0.94(0.08,11.27)$ \\
\hline $\begin{array}{l}\text { Fasting Blood sugar } \\
\mathrm{mg} / \mathrm{dl}\end{array}$ & & & & $1.016(1.01,1.02)^{*}$ & $1.01(1.01,1.02)^{*}$ \\
\hline
\end{tabular}

A family history of hypertension had higher odds of having hypertension compared to those who did not have a family history (aOR: 3.07, 95\% CI: 1.88 to 5.02). The odds of being hypertensive was 46\% (95\% CI 7\% to $69 \%$ ) lower for underweight as compared to normal weight. Being overweight compared to normal has almost 3 (aOR: 2.66, 95\% CI: 1.55 to 4.56) times more likelihood of having to have hypertension. Obese compared to normal weight had higher odds of hypertension (aOR: 3.46, 95\% CI: 1.34 to 8.92). Age, fasting blood glucose, family history of hypertension, and body mass index, had statistically significant association with hypertension. The possibility of having hypertension increased with advancing age. Residence, marital status, academic status, occupation, and vegetable $\&$ fruit consumption in a week were not significantly associated with hypertension. 


\section{Discussion}

Hypertension is a global public health issue which rarely causes symptoms in the early stages and many people go undiagnosed $^{3}$. The objective of this study was to determine the prevalence and associated factors of hypertension in Amhara Regional State city and its' surrounding rural districts in NorthWest Ethiopia. The overall prevalence of hypertension in the study area was $11.4 \%$ which was lower than other studies conducted in Ethiopia Gondar Northwest Ethiopia, 27.9\% $\%^{7}$, Durame South Ethiopia $22.4 \%{ }^{9}$, Ethiopian population $19.6 \%{ }^{8}$, pooled prevalence in sub-Saharan African ${ }^{6}$ and Uganda $30.5 \%{ }^{16}$. This discrepancy could be due to age difference of study participants; this study included a younger population $\geq 18$ years old while other studies included older populations. For example, a study done in Gondar used aged $\geq 35$ years old, in Durame ${ }^{9}$ study adults older than 31 years and the Ethiopia population ${ }^{8}$ and in SSA study were a pooled prevalence of systematic review and meta-analyses $^{6}$ which would incorporate researches with different methodologies and study designs. However, the prevalence in the current study is slightly higher than a study done in Sidama Southern Ethiopia 9.9\% ${ }^{11}$.

Hypertension is a highly prevalent condition with numerous health risk factors, and the incidence is greatest among older adults. In this study, age had a significant association with hypertension, besides it proved that with increasing age the risk of hypertension occurrence also highly increased. This is in line with several studies ${ }^{6-9,17,18}$. It was also found that with increasing fasting blood glucose level the prevalence of hypertension also increased. The finding is congruent with the study done in Dabat districtand Gondar NorthWest Ethiopia ${ }^{7}$. This is because an increased blood sugar potentially increases insulin and leptin level and these causes blood pressure to increase ${ }^{19}$.

It is known that fruits and vegetables are high in potassium, magnesium and fiber. In addition they are low in sodium contents. So, consuming such varieties of foods will help in reducing the risk of hypertension. Even if it is well established that the consumption of fruits and vegetables decreases the risk of hypertension, the current study did not revealed a significant association and this finding is congruent with findings from a study done in Gondar Northwest Ethiopia ${ }^{10}$ and $\mathrm{Nepal}^{20}$. This might depend on the respondents' perception and response for questions that assess the fruit and vegetable consumption during the interview.

Risk factors like family history of hypertension, being overweight and obesity were significantly associated with hypertension and this agrees with previous studies ${ }^{6-9,17,18,21}$. Educational status had no association with being hypertensive which is contrary to a study done in Uganda that revealed individuals who attained tertiary education (Diploma and above) were nearly 3 times more likely to be hypertensive compared to those who never went to school. This difference may be due to; in this study almost $86 \%$ of subjects were not passed through tertiary education which could show these people would have less likely to have a sedentary life such as prolonged sitting in an office, rather they would have exposure to vigorous activity.

Congruent with Uganda study ${ }^{16}$; residence and occupation were not significantly associated with the prevalence of hypertension.

\section{Strength and limitation}

The strength of this study might be inclusion of a relatively large sample size, using objective measurements and also including a younger adult age group; which could contribute to preventing an overestimation of the overall prevalence of hypertension in the general population. The limitations of our study included; alcohol consumption reported as only frequency and type of alcohol, it do not consider the amount of alcohol consumed due to the fact that local drinks measurement and alcohol volume is difficult, and varies.

\section{Conclusion}

Compared to other studies, the current study revealed that lower prevalence of hypertension. The study also showed that 1 among every 3 and 1 among every 9 study participants were found to have pre-hypertension and hypertension respectively.

A family history of hypertension, body mass index and raised fasting blood glucose were found to be the predictors of hypertension.

Community-based prevention and control strategies such as mass screening of community at certain inter- 
vals would contribute to the reduction and control of the growing prevalence of hypertension.

\author{
Abbreviations \\ BMI; Body mass index \\ BP; Blood pressure \\ NCD; Non-communicable diseases \\ WC; waist circumference \\ WHR; Waist to hip ratio
}

\section{Ethics approval and consent to participate}

Ethical approval and clearance were obtained from Institutional Review Board of Bahir Dar University prior to enrollment. After clearly explaining the objective of the study, verbal consent was obtained from each participant before conducting the interview and measurements. All identified hypertensive and pre-hypertensive individuals were referred to health institutions. Data was kept confidentially and communicated without disclosing identity.

\section{Consent for publication}

Not applicable.

\section{Availability of data and material}

Data sets supporting the conclusion of this article within the article and its additional file.

\section{Competing interests}

None declared.

\section{Funding}

Bahir Dar University funded this research project.

\section{Author contributions}

WAT conceived and designed the study: WAT, TDT, AS, \& YS lead the study process. TDT, WAT, AS \& YS analyzed the data. TDT, AS \& WAT prepared the manuscript. All authors read and approved the manuscript.

\section{Acknowledgment}

We would like to appreciate the Bahir Dar city and Bahir Dar surrounding district administrations, the study participants, and data collectors for their cooperation and support.

\section{References}

1. World Health Organization. STEPS: A framework for surveillance [Internet]. 2003. Available from: http:// www.who.int/ncd_surveillance

2. Mathers CD, Loncar D. Projections of global mortality and burden of disease from 2002 to 2030. PLoS Med. 2006;311:2011-30.

3. WHO. Global Status Report on noncommunicable diseases. Switzerland; 2014.

4. WHO. A Global Brief on Hypertension [Internet]. A global brief on hypertension. 2013. Available from: http://ish-world.com/downloads/pdf/global_brief_hypertension.pdf

5. Adeloye D, Basquill C. Estimating the prevalence and awareness rates of hypertension in Africa: A systematic analysis. PLoS One. 2014;98:1-17.

6. Ataklte F, Erqou S, Kaptoge S, Taye B, Echouffo-Tcheugui JB, Kengne AP. The burden of undiagnosed hypertension in sub-Saharan Africa: A systematic review and meta-analysis. Hypertension. 2015;652:291-8.

7. Abebe SM, Berhane Y, Worku A, Getachew A. Prevalence and associated factors of hypertension: A crossectional community-based study in Northwest Ethiopia. PLoS One. 2015;104:1-11.

8. Kibret KT, Mesfin YM. Prevalence of hypertension in Ethiopia : a systematic meta-analysis. Public Health Rev. 2015;3615.

9. Helelo TP, Gelaw YA, Adane AA. Prevalence and associated factors of hypertension among adults in durame town, Southern Ethiopia. PLoS One. 2014;911:1-9.

10. Awoke A, Awoke T, Alemu S, Megabiaw B. Prevalence and associated factors of hypertension among adults in Gondar, Northwest Ethiopia: a community based cross-sectional study. BMC Cardiovasc Disord. 2012;121:113.

11. Giday A, Tadesse B. Prevalence, and determinants of hypertension in rural and urban areas of southern Ethiopia. Ethiop Med J. 2011;492:139-47.

12. Central Statistical Agency [Ethiopia] and ICF International. Central Statistical Agency [Ethiopia] and ICF International. Ethiopia Demographic and Health Survey 2011. Addis Ababa, Ethiopia, and Calverton, Maryland, USA: Central Statistical Agency and ICF International. 2012.

13. Abebe SM, Berhane Y, Worku A, Assefa A. Diabetes mellitus in North West Ethiopia : a community-based study. BMC Public Health. 2014;1497:7-9.

14. World Health Organization. Chronic diseases and health promotion: a Stepwise approach to surveillance 
STEPS [Internet]. 2010. Available from: http://www. who.int/chp/steps/instrument/STEPS_Instrument_ V3.1.pdf?ua $=1$

15. Giday A, Wolde M, Yihdego D. Hypertension, obesity and central obesity in diabetics and nondiabetics in Southern Ethiopia. Ethiop J Heal Dev. 2010;242:145-7.

16. Guwatudde D. Prevalence factors associated with Hypertension in Rukungiri District, Uganda -A Community-Based Study. Afr Health Sci. 2009;993:153-60.

17. Joshi MD, Ayah R, Njau EK, Wanjiru R, Kayima JK, Njeru EK, et al. Prevalence of hypertension and associated cardiovascular risk factors in an urban slum in Nairobi, Kenya: A population-based survey. BMC Public Health. 2014;141177:1-10.

18. Oliveira GF, Oliveira TRR, Ikejiri AT, Andrus MP, Galvao TF, Silva MT, et al. Prevalence of hypertension and associated factors in an indigenous community of Central Brazil: A population-based study. PLoS One. 2014;91:1-6.

19. Mercola. Strategies to prevent hypertension [Internet]. Strategies to help prevent hypertension. 2014 [cited 2016 Oct 9]. Available from: http://articles.mercola.com/ sites/articles/archive/2015/02/25/sugar-blood-pressure.aspx

20. Dhungana RR, Pandey AR, Bista B, Joshi S, Devkota S. Prevalence and Associated Factors of Hypertension: A Community-Based Cross-Sectional Study in Municipalities of Kathmandu, Nepal. Int J of Hypertension Incid. 2016;2016:1-10 PubMed.

21. Méndez-chacón E, Santamaría-Ulloa C, Rosero- L. Factors associated with hypertension prevalence, unawareness and treatment among Costa Rican elderly. 2008;11:1-11. 